\title{
Convexity and Mathability
}

\author{
Antal Joós ${ }^{1}$, Attila Kovari ${ }^{2,3,4}$ \\ ${ }^{1}$ University of Dunaújváros, Institute of Computer Engineering, Department of \\ Mathematics, Táncsics M. u. 1/a, 2400 Dunaújváros, Hungary, joosa@uniduna.hu \\ ${ }^{2}$ University of Dunaújváros, Institute of Engineering, Department of Natural \\ Science, Táncsics M. u. 1/a, 2400 Dunaújváros, Hungary, kovari@uniduna.hu \\ ${ }^{3}$ Óbuda University, Alba Regia Technical Faculty, Budai út 45, 8000 \\ Székesfehérvár, Hungary, kovari.attila@amk.uni-obuda.hu \\ ${ }^{4}$ John von Neumann University, GAMF Faculty of Engineering and Computer \\ Science, Izsáki u. 10, 6000 Kecskemét, Hungary, \\ kovari.attila@gamf.uni-neumann.hu
}

\begin{abstract}
Mathability refers to a branch of cognitive infocommunications that investigates any combination of artificial and natural cognitive capabilities relevant to mathematics, including a wide spectrum of areas ranging from low-level arithmetic operations to highlevel symbolic reasoning. In connection with investigations related to mathability and to applications of computer-assisted methods for studying mathematical problems, in this paper, animation of the planar hyperconvex sets of radius $r$ is presented. This animation helps us understand some properties of hyperconvex sets and to see the differences between convexity and hyperconvexity.
\end{abstract}

Keywords: Mathability; Cognitive Infocommunications; Computer Assisted Methods; Animation; Convex set; Hyperconves set of raduis r; Spindle convex set; Ball polyhedron

\section{Introduction}

Mathability refers to a branch of cognitive infocommunications that investigates any combination of artificial and natural human cognitive capabilities relevant to mathematics, including a wide spectrum of areas ranging from low-level arithmetic operations to high-level symbolic reasoning. The concept was introduced in the paper [1] related to the $4^{\text {th }}$ IEEE International Conference on Cognitive Infocommunications (CogInfoCom) in 2013. Mathability refers to devices with high mathematical and logical potential and is defined as human mathematical ability [8]. Mathability mainly discusses what new assimilation methods are used to process information and how people use this ability to build their knowledge using problem-solving and experiences as well as high-level mathematics 
applications [8]. Its educational aspects were investigated, among others, in [5][13], while [14]-[18] papers focus on human cognitive related aspects of CogInfoCom and how people can communicate with machines to possess new knowledge. Questions related to mathability and to computer-based methods for investigations of mathematical problems have been studied by several authors during recent years [19]-[23]. Computer-aided solutions of mathematical problems were presented in [22], [26] and some of its further general properties were described in the papers [2] and [3] and in the book [4]. In this paper, we also would like to contribute to these investigations. We present a computer-assisted method for a visualization related to the so-called hyperconvex discs of radius $r$.

Although convexity is one of the oldest concepts in geometry, it is used to investigate some modern phenomena in mathematics, i.e. this property is used in the qualitative theory of differential equations as well [24], [25].

The students meet the convexity several times during the education. In this paper, the basics of convexity and some generalizations of convexity will be introduced. The paper [26] motivated us to write an animation of hyperconvex discs of radius $r$. The animation is developed in GeoGebra available at https://www.geogebra.org/.

The hyperconvexity is a generalisation of convexity. Such kinds of generalisation of convexity shoves us the deeper attributes of convexity. The presented animation helps us understand some properties of hyperconvex sets and to see the differences between convexity and hyperconvexity.

\section{The Convexity}

The $n$-dimensional Euclidean space is denoted by $\mathbb{R}^{n}$. The notation $\cap$ means the intersection of sets. The points and vectors are identified in a natural way. In this paper, $x y$ will also denote the length of the segment $x y$.

In this section we write the basic concepts of convexity.

In the school of geometry, a figure is called convex if it contains all segments if the endpoints of the segments lie in the figure. The next definition is the same.

Definition 2.1. The set $C$ is convex if $x, y \in C$ implies that for any $\lambda \in[0,1]$ we have

$\lambda x+(1-\lambda) y \in C$.

Definition 2.2. The set $N$ is non-convex if it is not convex, i.e. there are at least two points $x, y \in N$, and a $\lambda$ number $(\lambda \in[0,1])$ such that

$\lambda x+(1-\lambda) y \notin N$. 
Example 2.1. In Figure 1 we can see a convex set (left) and a non-convex set (right). Indeed, the right set is not convex, the midpoint $m$ of the segment $p q$ does not lie in the set.
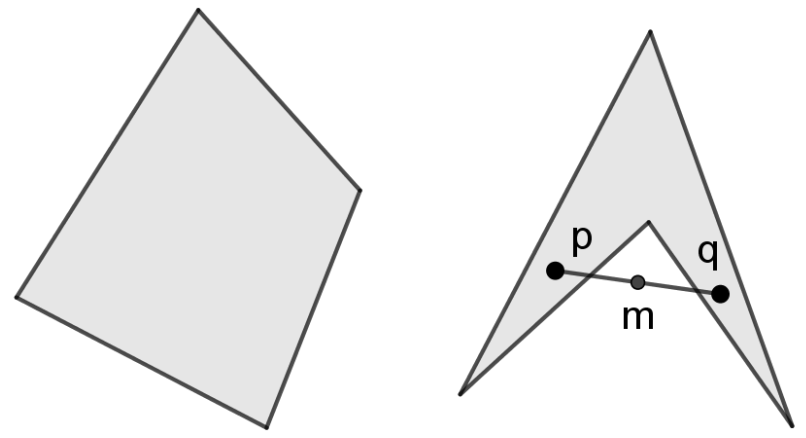

Figure 1

A convex set (left) and a non-convex set (right)

Example 2.2. The empty set is convex. The straight line segment is convex. The whole plane is convex.

The convex combination of the two points $x$ and $y$ is the set $\lambda x+(1-\lambda) y$ for all $\lambda \in[0,1]$ which is the straight line segment connecting the points $x$ and $y$. The convex combination of finitely many points is the following.

Definition 2.3. The convex combination of the points $x_{1}, \ldots, x_{k} \in \mathbb{R}^{n}$ is the linear combination

$\lambda_{1} x_{1}+\cdots+\lambda_{k} x_{k}$

for

$\lambda_{1} \geq 0, \ldots, \lambda_{k} \geq 0$ and $\lambda_{1}+\cdots+\lambda_{k}=1$.

Example 2.3. The set of all convex combinations of two different points is a straight line segment. The set of all convex combinations of three non-collinear points is a triangle.

Remark 2.1. The set $C$ is convex if and only if all the convex combinations of the points $x_{1}, \ldots, x_{k} \in \mathbb{R}^{n}$ lie in the set $C$.

Theorem 2.1. The intersection of convex sets is convex.

This implies the next definition.

Definition 2.4. The convex hull of the set $S \in \mathbb{R}^{n}$ is the intersection of all convex sets containing $S$.

Remark 2.2. The convex hull of a set is convex.

Example 2.4. The convex hull of a convex set $C$ is $C$. 
Example 2.5. The convex hull of three different non-collinear points $x_{1}, x_{2}, x_{3}$ is the triangle of vertices $x_{1}, x_{2}, x_{3}$.

Definition 2.5. The Minkowski sum of the sets $S_{1}, S_{2} \in \mathbb{R}^{n}$ is the set

$\left\{s_{1}+s_{2}: s_{1} \in S_{1}, s_{2} \in S_{2}\right\}$.

Notation: $S_{1}+S_{2}$.

Example 2.6. The Minkowski sum of two non-parallel segments is a parallelogram.

Theorem 2.2. Let $C_{1}$ and $C_{2}$ be two convex sets in $R^{n}$. The translation $C_{1}+p$ is convex. The scaling $\alpha C_{1}$ is convex. The orthogonal projection of the set $C_{1}$ is convex. The Minkowski sum $C_{1}+C_{2}$ is convex.

\section{Some Generalizations of Convexity}

\subsection{The m-convexity}

Toader [27] introduced the m-convexity in the following way.

Definition 3.1.1. Let $m \in[0,1]$ be a fixed number. The set $C \in R^{n}$ is m-convex if

$t x+m(1-t) y \in C$

for all elements $x, y \in C$ and for each $t \in[0,1]$.

Example 3.1.1. If $m=1$, then the definitions convex and $m$-convex are the same.

It is a consequence of the definition, that if $m \neq 1$, then it is necessary to consider the origin as well.

Example 3.1.2. If $m=0.5$, then the m-convex set containing the points $x$ and $y$ contains the point $\frac{m}{m+1}(x+y)$ as well (see, e.g. [26]) 


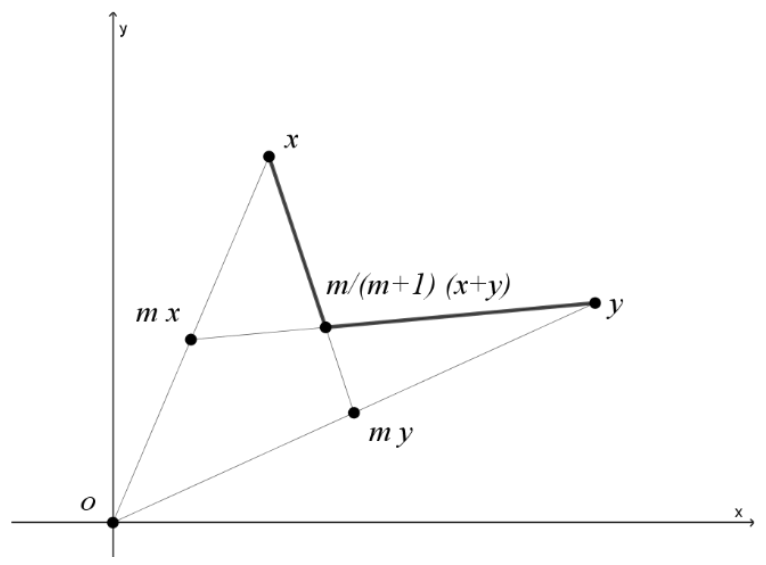

Figure 2

The line connecting the points $x$ and $y$ in an m-convex set

Definition 3.1.2. The $m$-convex combination of the points $x_{1}, \ldots, x_{k} \in \mathbb{R}^{n}$ is the linear combination

$\lambda_{1} x_{1}+m\left(\lambda_{2} x_{2}+\cdots+\lambda_{k} x_{k}\right)$

for

$\lambda_{1} \geq 0, \ldots, \lambda_{k} \geq 0$ and $0<\lambda_{1}+\cdots+\lambda_{k} \leq 1$.

Definition 3.1.3. The $m$-convex hull of the set $S \in \mathbb{R}^{n}$ is the intersection of all m-convex sets containing $S$.

Theorem 3.1.1 [28] The set $S$ is m-convex if and only if $S$ is the set of all $\mathrm{m}$-convex combinations of points lying in $S$.

Theorem 3.1.2 [28] The m-convex hull of the set $S$ is the set of all $\mathrm{m}$-convex combinations of points lying in $S$.

Theorem 3.1.3 [28] Let $S$ be a set containing the origin $o$. The set $S$ is m-convex if and only if for all $x, y \in S$ the set $\operatorname{conv}\left(o, x, \frac{m}{m+1}(x+y)\right)-\{o\}$ is contained in $S$.

Example 3.1.3. The m-convex hull of the two different points $x, y$ and the origin $o$ is the (degenerate) quadrangle $o x \frac{m}{m+1}(x+y) y$ (Figure 2).

In [21] and [25] we can find an animation of m-convex hull of finitely many points if $\mathrm{m}$ is varied. This paper motivated us to produce a similar animation for hyperconvex sets of radius $r$. 


\subsection{The Hyperconvex Sets of Radius $r$}

Definition 3.2.1. The $n$-dimensional ball (or shortly $n$-ball) of radius $r$ and center $c$ in $R^{n}$, denoted by $B(r, c)$, is $\left\{x \in R^{n}: x c \leq r\right\}$. If $n=2$, then the ball is called disc.

Definition 3.2.2. The $n$-dimensional sphere (or shortly $n$-sphere) of radius $r$ and center $c$ in $R^{n}$ is $\left\{x \in R^{n}: x c=r\right\}$. If $n=2$, then the sphere is called circle.

Definition 3.2.3. Let $x, y \in R^{n}$. If $x y<2 r$, then the spindle of radius $r$ (or shortly spindle) of $x$ and $y$ is defined as the union of circular arcs with endpoints $x$ and $y$ that are of radii at least $r$ and shorter than a semicircle of radius $r$. If $x y=2 r$, then the spindle of $x$ and $y$ is defined as the disc of radius $r$ and center $(x+y) / 2$. If $x y>2 r$, then the spindle of $x$ and $y$ is defined as $\emptyset$.

Remark 3.2.1. The spindle of $x$ and $y$ is the intersection of the balls of radii $r$ and containing $x$ and $y$.

Example 3.2.1. In Figure 3 can be found a spindle of radius 1 of $x$ and $y$ on the plane if $x y<2$.

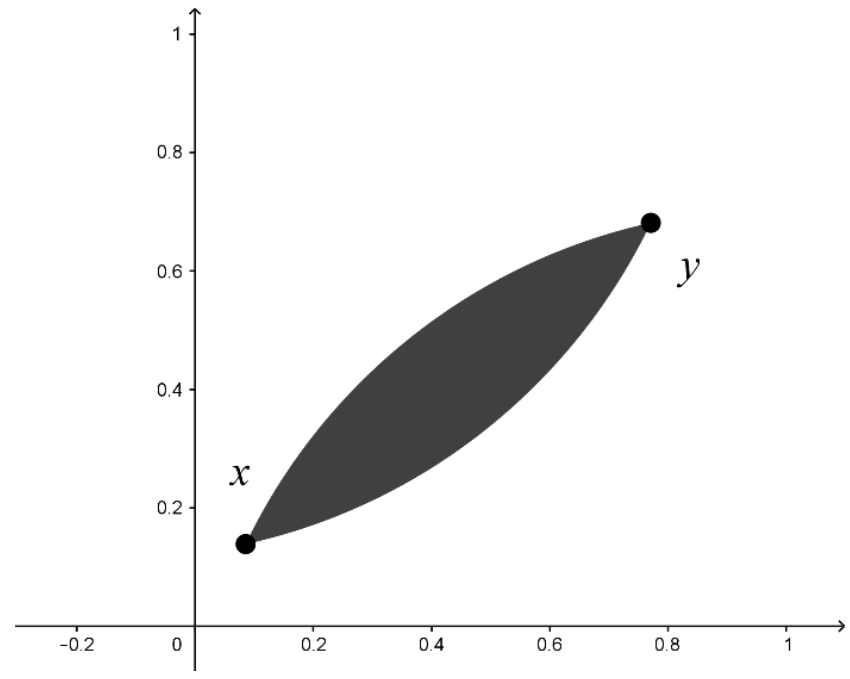

Figure 3

The spindle of $x$ and $y$

Definition 3.2.4. Let $C$ be the set such that the diameter of $C$ is less than or equal to $2 r$. The set $C$ is spindle convex (of radius $r$ ) if $x, y \in C$ implies that the spindle of $x$ and $y$ is a subset of $C$.

Definition 3.2.5. The circumradius, denoted by $\operatorname{cr}(C)$ of a bounded set $\mathrm{C}$ in $R^{n}$ is defined as the radius of the unique smallest ball that contains $C$. If $C$ is unbounded, then $\operatorname{cr}(C)=\infty$. 
Definition 3.2.6. A set $C$ in $R^{n}$ is hyperconvex of radius $r$ (or shortly hyperconvex) if is the intersection of $n$-balls of radius $r$.

Remark 3.2.2. Observe if we consider half-spaces as balls of infinite radius, then the hyperconvexity of radius $r$ and (linear) convexity are the same.

Definition 3.2.7. Let $C$ be a finite set in $R^{n}$ such that $\operatorname{cr}(C) \leq r$. The ballpolyhedron of radius $r$ (or shortly ball-polyhedron) (generated by $C$ ) is the intersection of the balls for radii $r$ and centers of points in $C$. If $n=2$, then a ballpolyhedron is called a disk-polygon.

Observe the ball-polyhedron of radius $r$ generated by $C$ is

$P=\bigcap_{c \in C} B(r, c)$.

First Mayer [29] considered ball-polyhedra in 1935 and called this property "überkonvex". Mayer's paper inspired several researchers in the first half of the $20^{\text {th }}$ Century e.g. [30]-[36]. 1980's we can find this property as $r$-convex or spindle convex of hyperconvex of radius $r$ see, e.g. [37]-[47].

Definition 3.2.8. If a ball $B$ contains a set $C$ in $R^{n}$ and a point $x$ lies on the boundary of $B$ and the boundary of $C$ at the same time, then $B$ supports $C$ at $x$.

Theorem 3.2.1. Let $C$ be a closed convex set in $R^{n}$ such that $\operatorname{cr}(C) \leq r$. The following are equivalent.

1) The set $C$ is spindle convex of radius $r$.

2) The set $C$ is the intersection of unit balls of radius $r$ containing $C$.

3) For every boundary point of $C$, there is a ball of radius $r$ that supports $C$ at that point.

Definition 3.2.9. The hyperconvex hull of radius $r$ of the set $S \in \mathbb{R}^{n}$ is the intersection of all hyperconvex sets of radius $r$ containing $S$.

\section{The Description of Animation}

We use the dynamic free software GeoGebra, which can be downloaded from https://www.geogebra.org/.

To have a GeoGebra file, which can be easily modified, we use scripts under buttons.

The first GeoGebra script under button1 in On Click is the input of points, a list which consists of the points, the default value of $r$, and a text. In this special case, we use six points. 


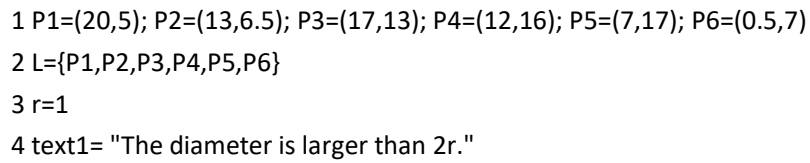

The JavaScript under button2 in On Click is the drawing of the hyperconvex set of radius $r$ generated by the points in the list $\mathrm{L}$. The code is the following.

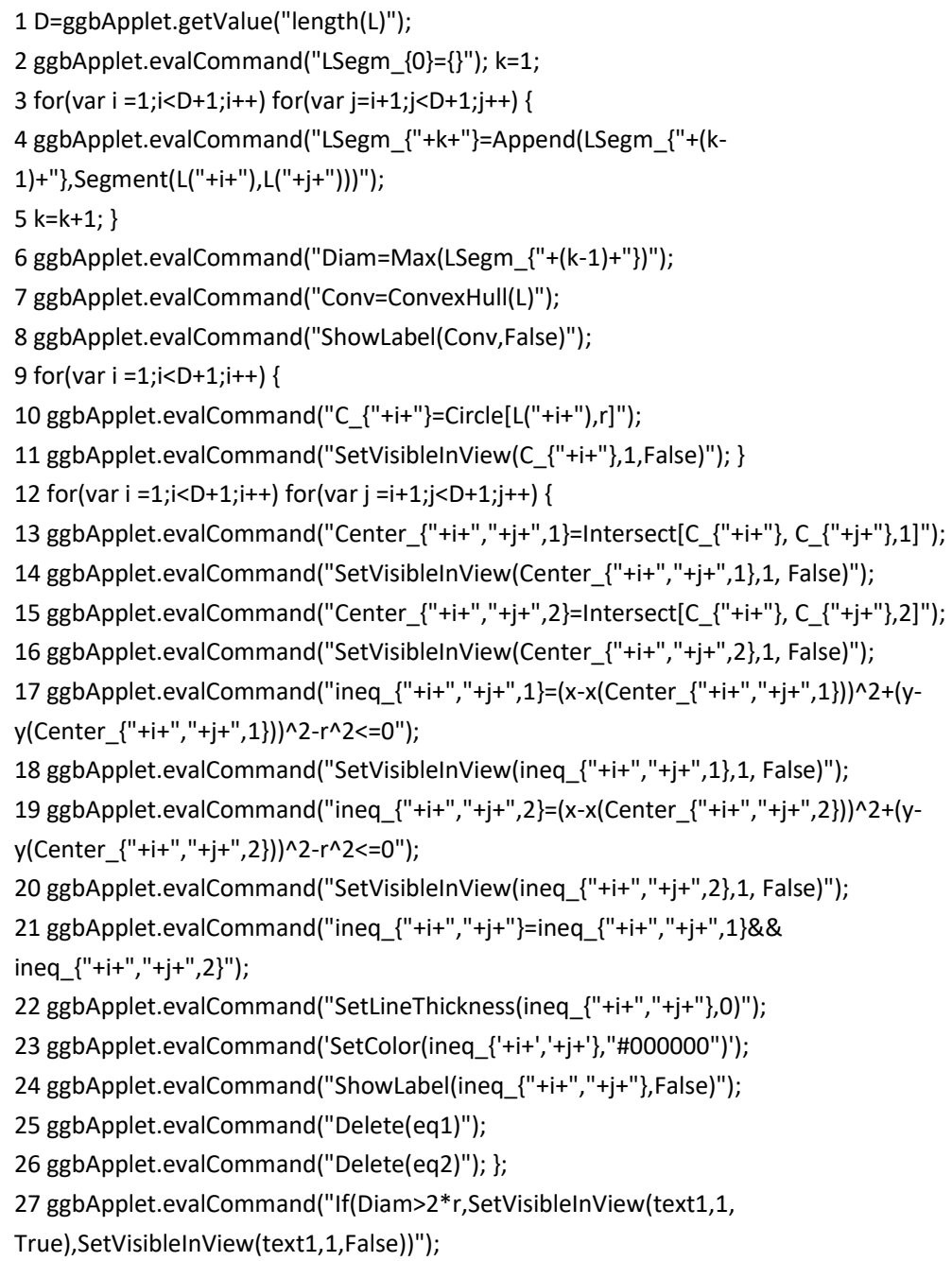

This is a rough algorithm. Our aim was visualization and not effectiveness. The first line adds the value of the length of the list L to the JavaScript code. Lines 2-6 determine the diameter of the point set lying in the list L. Since GeoGebra is a dynamic language the modification of the points lying in $\mathrm{L}$ implies the modification of the diameter calculated by this code in real-time. Lines $7-8$ produce the convex 
hull of the point set lying in the list L. Lines 9-26 define the spindles of the pairs of points in the list $\mathrm{L}$. Line 27 hides the text text1 if the diameter of $\mathrm{L}$ is less than or equal to $2 r$. The result is the hyperconvex hull of radius $r$ generated by the points in L. If we let show the object $r$ as a slide between 0.01 and 5, then we can vary the radius $r$ in the hyperconvex set. If we switch on the animation of $r$, then in Figures 4 and 5 we can see a selection of six stages of the hyperconvex hull of radius $r$ of the list of points given for the values $r=1,1.2,1.4,1.6,1.8$ and 5 .
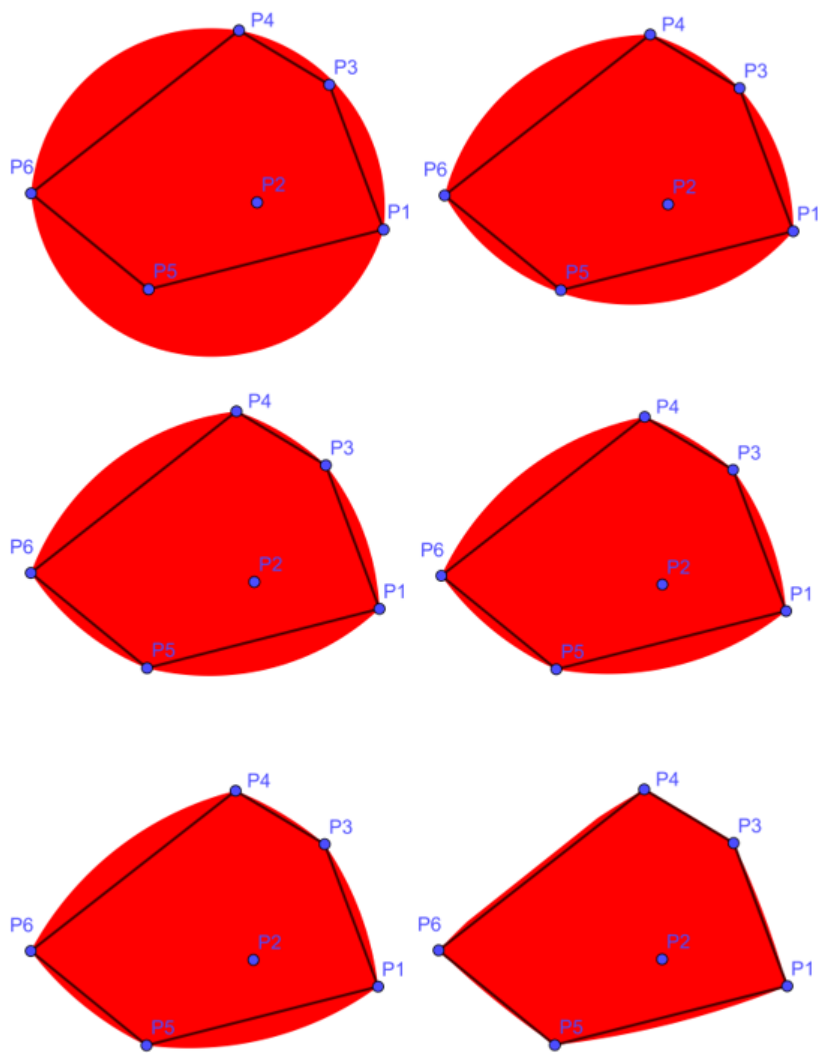

Figure 4

Some stages from the animation

\section{Conclusion}

The results presented here are connected to the investigations of mathability (cf. [1] and [4].) Nowadays hyperconvexity is a popular generalisation of convexity in the literature of discrete and convex geometry (see e.g. [43]).

Convexity is a wide range applicable concept in mathematics. The first step considering hyperconvex sets is drawing such a set on a piece of paper. This dynamic animation enables us to draw this figure. In order to imagine a hyperconvex set in higher dimensions we have to understand the planar case. 
Since a generalization of convexity can be challenging to imagine or understand, it is important to visualize hyperconvexity. We can find serious theorems in the literature considering the difference between linear convexity and a generalization of convexity. If we use such simple animations, then we can make conjecture about new theorems and about the difference between the two kinds of convexity easier.

The presented method inspires us to visualize geometric properties of point sets in GeoGebra. GeoGebra supports the script commands as we can see in this paper. It could be a different opportunity to create a new tool in GepGebra to visualize the hyperconvex hull of a finite point set.

\section{Acknowledgement}

This work was supported by EFOP-3.6.1-16-2016-00003 funds. Establishment of long-term $\mathrm{R}$ and $\mathrm{D}$ and I processes at the University of Dunaújváros.

\section{References}

[1] Baranyi P., Gilányi A.: Mathability: emulating and enhancing human mathematical capabilities, Proceedings of the $4^{\text {th }}$ IEEE International Conference on Cognitive Infocommunications (CogInfoCom), Budapest, Hungary, 2013, pp. 555-558

[2] Baranyi P., Csapo A., Varlaki P.: An overview of research trends in coginfocom. Proceedings of the $18^{\text {th }}$ International Conference on Intelligent Engineering Systems (INES), Tihany, Hungary, 2014, pp. 181-186

[3] Török M., Tóth J., Szöllösi A.: Foundations and perspectives of mathability in relation to the coginfocom domain, Proceedings of the $4^{\text {th }}$ IEEE International Conference on Cognitive Infocommunications (CogInfoCom), Budapest, Hungary, 2013, pp. 869-872

[4] Baranyi P., Csapo A., Sallai G.: Cognitive Infocommunications (CogInfoCom) Springer, 2015

[5] Chmielewska K. et al: Learnability - are we ready for distance learning?, Proceedings of the $11^{\text {th }}$ IEEE International Conference on Cognitive Infocommunications (CogInfoCom), Online, 2020, pp. 465-470

[6] Biró P., Csernoch M.: Deep and surface metacognitive processes in nontraditional programming tasks, Proceedings of the $5^{\text {th }}$ IEEE Conference on Cognitive Infocommunications (CogInfoCom), Vietri sul Mare, Italy, 2014, pp. $49-54$

[7] Kővári A., Rajcsányi-Molnár M.: Mathability and Creative Problem Solving in the MaTech Math Competition. Acta Polytechnica Hungarica, 17(2), 2020, pp. 147-161

[8] Chmielewska K., Gilanyi A.: Educational context of mathability, Acta Polytechnica Hungarica, Vol. 15, No. 5, 2018, pp. 223-237 
[9] Biró P., Csernoch M.: Deep and surface metacognitive processes in nontraditional programming tasks, Proceedings of the $5^{\text {th }}$ IEEE Conference on Cognitive Infocommunications (CogInfoCom), Vietri sul Mare, Italy, 2014, pp. $49-54$

[10] Chmielwska K. et al: Mathability and mathematical cognition, Proceedings of the $7^{\text {th }}$ IEEE Conference on Cognitive Infocommunications (CogInfoCom), Wroclaw, Poland, 2016, pp. 245-250

[11] Szi B., Csapo A.: An outline of some human factors contributing to mathability research, Proceedings of the $5^{\text {th }}$ IEEE Conference on Cognitive Infocommunications (CogInfoCom), Vietri sul Mare, Italy, 2014, pp. 583586

[12] Chmielwska K., Gilányi A.: Mathability and computer aided mathematical education, Proceedings of the $6^{\text {th }}$ IEEE Conference on Cognitive Infocommunications (CogInfoCom) Győr, Hungary, 2015, pp. 473-477

[13] Piró P., Csernoch M.: The mathability of computer problem solving approaches. Proceedings of the $6^{\text {th }}$ IEEE Conference on Cognitive Infocommunications (CogInfoCom), Győr, Hungary, 2015, pp. 111-114

[14] Katona J. et al: Using Eye- Tracking to Examine Query Syntax and Method Syntax Comprehension in LINQ, Proceedings of the $12^{\text {th }}$ IEEE International Conference on Cognitive Infocommunications (CogInfoCom), Naples, Italy, 2020, pp. 437-444

[15] Kővári, A., Katona, J., Costescu, C.: Evaluation of Eye-Movement Metrics in a Software Debugging Task using GP3 Eye Tracker. Acta Polytechnica Hungarica, 17(2), 2020, pp. 57-76

[16] Námesztovszky, Z., \& Boros, O. (2019). The Implementation of Projects which Develop Both Soft and Interdisciplinary Skills Using Micro:bit. Journal of Applied Technical and Educational Sciences, 9(2), 42-51

[17] Kővári A., Katona J., Costescu C.: Quantitative Analysis of Relationship Between Visual Attention and Eye-Hand Coordination. Acta Polytechnica Hungarica, 17(2), 2020, pp. 77-95

[18] Orosz, B. et al: Digital education in digital cooperative environments. Journal of Applied Technical and Educational Sciences, 9(4), 2019, 55-69

[19] Borus G. Gy. et al: On a computer program for solving systems of functional equations, Proceedings of the $4^{\text {th }}$ IEEE International Conference on Cognitive Infocommunications (CogInfoCom), Budapest, Hungary, 2013, p. 939

[20] Gilányi A.: Solving linear functional equations with computer, Math. Pannon., Vol. 9, No. 1, 1998, pp. 57-70 
[21] Borus G. G., Gilányi A.: Computer assisted solution of systems of two variable linear functional equations. Aequationes mathematicae, 94(4), 2020, pp. $723-736$

[22] Gilányi A., Merentes N., Quintero R.: Presentation of an animation of the mconvex hull of sets, Proceedings of the $7^{\text {th }}$ IEEE Conference on Cognitive Infocommunications (CogInfoCom), Wrocław, Poland, 2016, pp. 307-308

[23] Borus G. Gy. et al: Solving systems of linear functional equations with computer, Proceedings of the $4^{\text {th }}$ IEEE International Conference on Cognitive Infocommunications (CogInfoCom), Budapest, Hungary, 2013, pp. 559-562

[24] Nagy B.: Analysis of the Biological Clock of Neurospora. J. Comp. Appl. Math., 2009, pp. 298-305

[25] Simon P., Farkas H., Wittmann M.: Constructing global bifurcation diagrams by the parametric representation method. J. Comp. Appl. Math., 1999, pp. $157-176$

[26] Gilányi A., Merentes N., Quintero R.: Mathability and an animation related to a convex-like property, Proceedings of the $7^{\text {th }}$ IEEE Conference on Cognitive Infocommunications (CogInfoCom), Wroclaw, Poland, 2016, pp. 227-232

[27] Toader G.: Some generalizations of the convexity. Proceedings of the Colloquium on Approximation and Optimization, Univ. Cluj-Napoca, ClujNapoca, 1985, pp. 329-338

[28] Lara T.: On m-Convexity on Real Linear Spaces. UPI Journal of Mathematics and Biostatistics, 2018, pp. 1-16

[29] Mayer, A. E.: Hyperconvex sets (Eine Überkonvexitat). Math. Z., 39, 1935, pp. 511-531

[30] Blanc E.: Sets on convex planes (Les ensembles surconvexes plans). Ann. Sci. Ecole Norm. Sup., 60 (3), 1943, pp. 215-246

[31] Buter J.: About convex sets in the plane (Überconvexe Mengen in der Ebene) Ak. Wetensch. Amsterdam Proc. 41, 1938

[32] Pasqualini L.: Superconvexity (Superconvexité). Bull. Cl. Sci. Acad. Belg., 25 (5), 1939, pp. 18-24

[33] Santaló L. A.: On plane hyperconvex figures. Summa Brasil. Math., 1, 1946, pp. 221-239

[34] Corput J. G.: About convex sets in the plane (Überkonvexe Mengen in der Ebene). Ak. Wetensch. Amsterdam Proc., 41, 1938

[35] Vincensini P.: Superconvex figures in the plane (Sur les figures superconvexes planes). Bull. Soc. Math. France, 64, 1936, pp. 197-208 
[36] Danzer L., Grünbaum B., Klee V.: Helly's theorem and its relatives. Proc. Sympos. Pure Math., Vol. VII, Amer. Math. Soc., Providence, R. I., 1963, pp. 101-180

[37] Fejes Tóth L.: Packing of r-convex discs. Studia Sci. Math. Hungar, 17, 1982, pp. 449-452

[38] Fejes Tóth, L.: Packing and covering with r-convex discs. Studia Sci. Math. Hungar, 18, 1982, pp. 69-73

[39] Bezdek K., Lángi. Zs, Naszódi M., Papez P.: Ball-polyhedra. Discrete Comput. Geom., 2007, pp. 201-230

[40] Kupitz Y, Martini H., Perles M.: Ball polytopes and the Vázsonyi problem. Acta Math. Hungar, 126, 2010, pp. 99-163

[41] Kupitz Y, Martini H., Perles M.: Finite sets in $\mathrm{R}^{\wedge} \mathrm{d}$ with many diameters a survey. Proceedings of the International Conference on Mathematics and Applications (ICMA-MU 2005, Bangkok), Mahidol University Press, Bangkok (Reprinted in a special volume of the East-West J. Math.: Contributions in Mathematics and Applications), 2005, 2007, pp. 91-112 (41-57)

[42] Bezdek K.: Lectures on sphere arrangements-the discrete geometric side, Fields Institute Monographs. New York: Springer, 2013

[43] Bezdek K.: Classical topics in discrete geometry, CMS Books in Mathematics/Ouvrages de Math'ematiques de la SMC. New York: Springer, 2010

[44] Fodor F., Fejes Tóth G.: Dowker-type theorems for hyperconvex discs. Period. Math. Hungar, 70, 2015, pp. 131-144

[45] Fodor F., Vígh V.: Variance estimates for random disc-polygons in smooth convex discs. arXiv, 2018

[46] Fodor F.: Inequalities for hyperconvex sets. Adv. Geom., 2016, pp. 337-348

[47] Bezdek A., Joós A.: Area minimization of special polygons. Acta Math. Hungar., 160 (1), 2020, pp. 33-44 